\title{
Diffuse Alveolar Haemorrhage in Childhood Systemic Lupus Erythematous With Good Response to Oral Steroid Therapy
}

\section{Pushpa Gurudas Kini, Karen Moras, Sandeep Kumar and Deepti Shetty}

Department of Paediatrics, Kasturba Medical College, Manipal Academy of Higher Education, Manipal, Karnataka, India.

\section{Correspondence:}

Dr Pushpa Gurudas Kini

Professor, Department of Paediatrics,

Kasturba Medical College

Manipal Academy of Higher Education,

Manipal, Karnataka, 576104, India.

Email: kini.pushpa@gmail.com.

Tel no: +91820-2922209

DOI: $10.3126 /$ jnps.v39i1.23145

Submitted on: 2019-03-15

Accepted on: 2020-03-14

Acknowledgements: None

Funding: Nil

Conflict of Interest: None declared

Permission form IRB: Yes
To cite this article: Kini PG, Moras K, Kumar S, Shetty D. Diffuse alveolar haemorrhage in childhood systemic lupus erythematous with good response to oral steroid therapy. J Nepal Paediatr Soc. 2018;39(1):59-62.

\section{ABSTRACT}

Diffuse alveolar hemorrhage (DAH) is a relatively rare and life threatening complication of systemic lupus erythematosus (SLE) in childhood. We report two distinct cases of SLE presenting with DAH as the sole manifestation of the disease during long term follow up. Both were successfully treated with oral prednisolone.

Key words: children; diffuse alveolar haemorrhage; haemoptysis; systemic lupus erythematosus 


\section{INTRODUCTION}

DAH is classically described as a triad of hemoptysis, falling haematocrit and radiographic appearance of new pulmonary infiltrates. ${ }^{1,2}$ The etiology of the immune mediated DAH includes ANCA-associated vasculitis, anti GBM disease, SLE, juvenile idiopathic arthritis, Behcet's disease and Henoch-Schonlein Purpura. Most of the studies related to DAH in SLE have described the concomitant presence of extra-pulmonary features especially active nephritis. ${ }^{3-5}$

\section{CASE REPORT}

Case 1:

A 10 years old girl presented with low grade fever, cough and hemoptysis for two weeks. There was no breathlessness. The child was treated for neonatal lupus erythematosus (NLE) at four weeks of age with maculopapular rash, thrombocytopenia and hepatosplenomegaly. Mother was on treatment for SLE and younger male sibling was also diagnosed as SLE at six weeks of age.

The weight was $27 \mathrm{~kg}$ and height was $125 \mathrm{~cm}$. Vitals were stable. Except for pallor, the general physical examination was unremarkable. Respiratory system examination revealed crepitations in right infra axillary area. CNS examination revealed spasticity of lower limbs

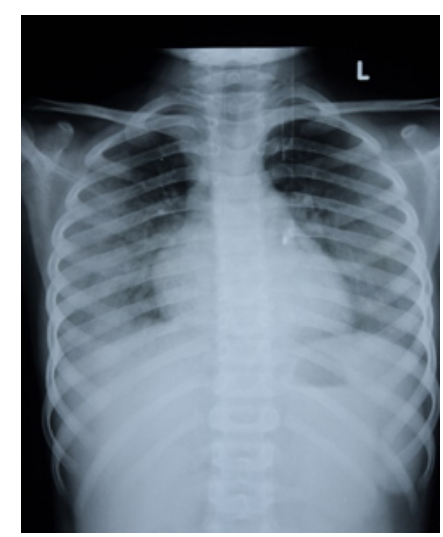

Figure 1. Non homogenous opacities in bilateral middle and lower zones

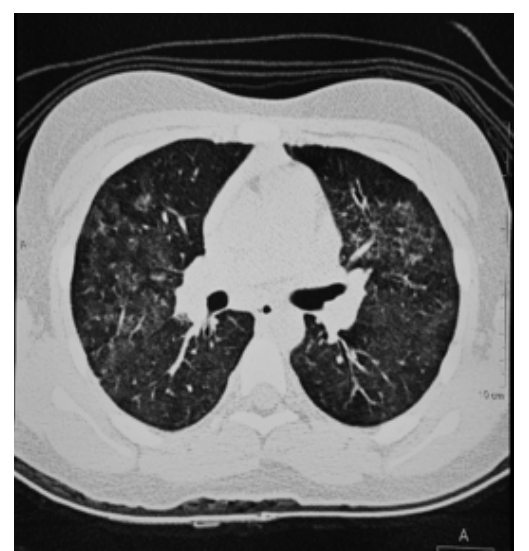

Figure 2. HRCT thorax showing bilateral ground glass alveolar opacities

suggestive of spastic diplegia secondary to intracranial haemorrhage in newborn period.

Haemogram revealed haemoglobin of $9.1 \mathrm{~g} / \mathrm{dl}$ with total leukocyte count (TLC) of $15.1 \times 10^{3} / \mu \mathrm{L}$ and platelet count of $408 \times 10^{3} / \mu \mathrm{L}$. Erythrocyte Sedimentation Rate (ESR) was $37 \mathrm{~mm}$ ( $1^{\text {st }}$ hour). There was no proteinuria / haematuria. Coagulation profile and renal function tests were normal. Serum C3 level was $121 \mathrm{mg} / \mathrm{dL}$ (normal: $90-160 \mathrm{mg} / \mathrm{dL}$ ) and $\mathrm{C} 4$ was $43 \mathrm{mg} / \mathrm{dL}$ (normal: $10-44 \mathrm{mg} / \mathrm{dL}$ ). Anti-nuclear antibody (ANA) profile was positive for anti-ribosomal $\mathrm{P}$ protein antibodies with anti-dsDNA titres of $>160 \mathrm{IU} / \mathrm{mL}$. Other auto-antibody profile including p-ANCA (anti-neutrophil cytoplasmic antibody), c-ANCA, anti-phospholipid antibody (APLA) and anti-glomerular basement membrane (GBM) antibody were negative. Chest $\mathrm{X}$-ray showed non-homogenous opacities in bilateral middle and lower zone (figure 1). High Resolution Computed Tomography (HRCT) thorax

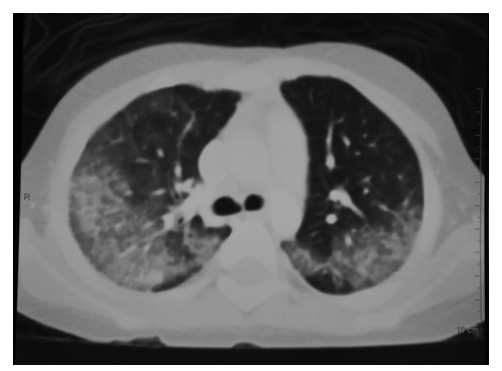

Figure 3. HRCT thorax showing bilateral diffuse ground glass opacities with interlobular septal 
revealed ground glass opacities suggestive of DAH (figure 2). Positron Emission Tomography (PET) confirmed the same.

The child was started on oral prednisolone $2 \mathrm{mg} /$ $\mathrm{kg}$ /day and haemoptysis resolved in next one week. Steroid was continued for six weeks followed by slow tapering. The child is being followed up. At six months of follow up is asymptomatic with normal chest $\mathrm{x}$ ray.

\section{Case 2:}

A seven years old girl presented with laboured breathing for two days. There was no fever, cough or hemoptysis or any other symptoms suggestive of systemic involvement. She was treated for SLE class II nephritis (renal biopsy proven) at three years of age for three years and was off treatment for 10 months.

The weight was $22 \mathrm{~kg}$ and height was $120 \mathrm{~cm}$. Heart rate was 140 beats/minute, respiratory rate was 54 breaths/minute and blood pressure was $110 / 60 \mathrm{mmHg}$. There was severe pallor. Except for tachypnea, respiratory system examination was normal.

Investigations revealed hemoglobin $5.6 \mathrm{~g} / \mathrm{dl}$; TLC $22.2 \times 10^{3} / \mu \mathrm{L}$; platelet count $201 \times 10^{3} / \mu \mathrm{L}$. Peripheral smear showed microcytic hypochromic picture with haemolysis. ESR was $82 \mathrm{~mm}$ ( $1^{\text {st }}$ hour). Coagulation profile was normal. Serum C3 level was $56 \mathrm{mg} / \mathrm{dl}$. There was no renal involvement though C3 was low. There was no haematuria. 24hour urine protein was $6 \mathrm{mg} / \mathrm{m}^{2} / \mathrm{hr}$. Chest $\mathrm{x}$ ray showed bilateral inhomogeneous opacities. HRCT thorax showed patchy areas of ground glass opacities with interlobular septal thickening (figure 3). ANA profile was positive for anti-ribosomal $\mathrm{P}$ protein antibodies.

The child was treated with IV antibiotics and oral prednisolone $(2 \mathrm{mg} / \mathrm{kg} /$ day $)$. Child responded and respiratory distress subsided over next 48 hours. Repeat chest $\mathrm{X}$ ray done showed improvement. Steroid was continued for six weeks followed by slow tapering.

\section{DISCUSSION}

The pulmonary manifestations of childhood SLE include pleural disease, lupus pneumonitis, interstitial lung disease, pulmonary haemorrhage, diaphragmatic dysfunction and pulmonary hypertension. ${ }^{2-5}$ The incidence of DAH ranges from $1-4 \%$ of children with SLE. ${ }^{3-7}$ In a study done by Singla et al., only seven out of 410 children were found to have $\mathrm{DAH}^{3}$ In a study done at our institution, of the 44 children, only two had DAH.

Autoantibody induced disruption of the alveolarcapillary basement membrane is believed to be responsible for DAH in SLE. Other factors include uremia, pulmonary infection and coagulopathy. ${ }^{2}$ Though DAH in SLE is not associated with a specific type of auto-antibody, the presence of APLA is found to be associated with more extensive disease. ${ }^{4}$ In the present study both the cases were positive for anti-ribosomal $\mathrm{P}$ protein antibodies.

The mean duration of SLE at the time of occurrence of DAH is reported to be seven years with a range of six months to 14 years. ${ }^{3}$ Few studies have reported DAH itself as the initial presentation of SLE. ${ }^{5,6}$ The onset is usually abrupt where symptoms develop over hours to days and may present with respiratory insufficiency. The occurrence of haemoptysis ranges from $25 \%-100 \%$ of cases. ${ }^{5-7}$ Some studies have reported a clinical picture mimicking bacterial pneumonia. ${ }^{7}$ The first case discussed is interesting as the child was treated for NLE and DAH as a part of SLE recurrence was noted at 10 years of follow up. Few cases of NLE progressing to SLE at a later age have been reported. ${ }^{8}$

Radiological imaging especially CT chest is the modality of choice for the diagnosis of DAH. Commonest radiological pattern is the diffuse alveolar interstitial filling pattern resulting in "ground glass" appearance. ${ }^{9}$ Steroids are the mainstay of treatment for DAH in SLE. A short course of high dose intravenous methyl prednisolone is commonly used. However, both children in the study responded to oral prednisolone. Immuno-suppressants like cyclophosphamide, cyclosporine and rituximab have been used. ${ }^{4-6,10}$ Most of the studies have reported lower survival rates ranging from 
8\%-70\%. In a study done by Kazzaz NM et al., thrombocytopenia and hypocomplementaemia were considered as poor prognostic factors in SLE complicated by DAH. ${ }^{10}$

\section{CONCLUSIONS}

DAH as a complication of SLE has occurred as the sole manifestation of relapse of SLE in the study. In both the cases, ANA profile was positive for antiribosomal $\mathrm{P}$ protein antibodies. Good response to oral prednisolone was noted in both children. DAH should be considered as a differential diagnosis in a child with SLE presenting with haemoptysis. In the absence of haemoptysis, new onset or worsening anaemia with appearance of new radiological infiltrates helps to suspect DAH.

\section{REFERENCES}

1. Susarla SC, Fan LL. Diffuse alveolar hemorrhage syndromes in children. Curr Opin Pediatr. 2007;19(3):314-320.DOI: 10.1097/ MOP.0b013e3280dd8c4a.

2. Vece TJ, de Guzman MM, Langston C, Fan LL. Diffuse Alveolar Hemorrhage in Children. In: Robert W. Wilmott TFB, Andrew Bush, Victor Chernick, Robin R. Deterding, Felix Ratjen, ed. Kendig \& Chernick's Disorders of the Respiratory Tract in Children. 9thed: Elsevier; 2019:893-902.

3. Singla S, Canter DL, Vece TJ, Muscal E, DeGuzman M. Diffuse alveolar hemorrhage as a manifestation of childhood-onset systemic lupus erythematosus. Hosp Pediatr. 2016;6:496-500. DOI: 10.1542/hpeds.2015-0281.

4. Araujo DB, Borba EF, Silva CA, Campos LM, Pereira RM, Bonfa E, et al. Alveolar hemorrhage: distinct features of juvenile and adult onset systemic lupus erythematosus. Lupus. 2012;21(8):872-7. DOI: 10.1177/0961203312441047.

5. Degaldo EA, Malleson PN, Pirie GE, Petty RE. The pulmonary manifestations of childhood onset systemic lupus erythematosus. Semin Arthritis Rheum. 1990;19:285-93. DOI: https://doi.org/10.1016/0049-0172(90)90051-G

6. Zamora MR, Warner ML, Tuder R, Schwarz MI. Diffuse alveolar haemorrhage and systemic lupus erythematosus. Clinical presentation, histology, survival and outcome. Medicine (Baltimore). 1997;76:192-202. DOI: 10.1097/00005792-199705000-00005

7. Badsha H, Teh CL, Kong KO, Tsui Y.L, Hiok H.C. Pulmonary haemorrhage in systemic lupus erythematosus. Semin Arthritis Rheum. 2004;33:414-21. DOI: https://doi.org/10.1016/j.semarthrit.2003.09.006.

8. Jackson R, Gulliver M. Neonatal lupus erythematosus progressing into systemic lupus erythematosus. A 15 -year follow-up. Br J Dermatol. 1979;101(1):81-6. DOI: 10.1111/j.1365-2133.1979.tb15297.x

9. Makino Y, Ogawa M, Ueda S, Ohto M. CT appearance of diffuse alveolar haemorrhage in a patient with systemic lupus erythematosus. Acta Radiol. 1993;34:634-5. PMID: 8240904

10. Kazzaz NM, Coit P, Lewis EE, McCune WJ, Sawalha AH, Knight JS. Systemic lupus erythematosus complicated by diffuse alveolar haemorrhage: risk factors, therapy and survival. Lupus Sci Med. 2015;2(1):e000117. DOI:10.1136/lupus-2015-000117 